\title{
Variação somaclonal nos descritores mínimos de tubérculo em batata
}

\author{
Somaclonal variation in minima descriptors of tuber in potato
}

\author{
Gisele Santiago $^{\mathrm{I}}$ Lia Rejane Silveira Reiniger ${ }^{\mathrm{II}}$ Joana Graciela Hanauer $^{\mathrm{I}}$ \\ Sidinei José Lopes ${ }^{\text {II }}$ Marta Stochero Deprá ${ }^{I I}$
}

\section{RESUMO}

Em batata, a cultura de tecidos é utilizada para recuperar cultivares infectadas por viroses, entretanto, o cultivo in vitro pode conduzir à variação somaclonal. O presente estudo teve como objetivos identificar somaclones e avaliar o efeito do tipo de explante e do tempo de subcultivo sobre a ocorrência de variantes somaclonais nas cultivares 'Asterix' $e$ 'Macaca'. Tubérculos produzidos em plantas regeneradas por organogênese direta e indireta de explantes derivados do cultivo de ápices caulinares de clones em subcultivo há 12 (clone novo) ou 70 (clone velho) meses em meio nutritivo MS e cultivadas em campo foram avaliados em relação a seis descritores mínimos da batata. As médias observadas foram comparadas aos padrões descritos para as cultivares e somente foram consideradas somaclones aquelas que foram enquadradas em uma classe fenotípica diferente do padrão da cultivar respectiva. Em 'Asterix' $e$ 'Macaca' ocorreram somaclones em quatro e dois descritores, respectivamente, contudo, apenas no formato e cor da polpa do tubérculo, houve variação somaclonal, simultaneamente, nas duas cultivares. Variantes somaclonais podem ser identificadas pelo uso dos descritores mínimos de tubérculo. 'Asterix' e 'Macaca' são, igualmente, suscetíveis à ocorrência de variação somaclonal, mas esse fenômeno afeta de maneira diferenciada os descritores mínimos nas duas cultivares. O tempo de subcultivo age diferencialmente sobre as características morfoagronômicas.Doze meses de subcultivo já são suficientes para originar somaclones. Segmentos apicais caulinares $e$ segmentos nodais, originados por organogênese direta ou indireta, são explantes igualmente instáveis para a produção de batata-semente.

Palavras-chave: Solanum tuberosum L., cultura de tecidos, estabilidade genética.

\begin{abstract}
In potato, tissue culture is used to retrieve cultivars infected by viruses, however, in vitro culture can lead to somaclonal variation. This study aimed to identify somaclones and evaluate the effect of type of explant and subculture time on the occurrence of somaclonal variants in cultivars 'Asterix' and 'Macaca'. Tubers produced in plants regenerated by direct and indirect organogenesis of shoot apical and nodal segments derived from the culture of shoot tips of clones in subculture for 12 (young clone) or 70 (old clone) months in nutritive medium MS and cultivated in field were assessed in six minima descriptors of the potato. The averages were compared to patterns described for the cultivars and somaclones were considered only those that were framed in a different phenotypic class from standard of cultivar. In 'Asterix' and 'Macaca' somaclonal variants were observed in four and two descriptors, respectively, however, only in the tuber shape and flesh color occurred somaclonal variation simultaneously in both cultivars. Moreover, remained stable the depth of the eyes and the greening of the tuber. Somaclonal variants can be identified by use of minima descriptors of tuber. 'Asterix' and 'Macaca' are equally susceptible to somaclonal variation. Twelve months of subculture is enough to cause somaclones in both cultivars. Shoot apical and nodal segments derived by direct or indirect organogenesis, are explants equally unstable to the production of seed potatoes.
\end{abstract}

Key words: Solanum tuberosum L., tissue culture, genetic stability.

'Programa de Pós-graduação em Agronomia, Universidade Federal de Santa Maria (UFSM), Santa Maria, RS, Brasil.

IDepartamento de Fitotecnia, Centro de Ciências Rurais (CCR), UFSM, 97105-900, Santa Maria, RS, Brasil. E-mail: liarsr@ufsm.br

*Autor para correspondência

IIICurso de Agronomia, UFSM, Santa Maria, RS, Brasil. 


\section{INTRODUÇÃO}

A batata (Solanum tuberosum L.) é a quarta cultura em importância econômica no mundo depois do trigo, do milho e do arroz; sendo cultivada em mais de 125 países e consumida por mais de um bilhão de pessoas (NASRIN, 2003). Em batata, a cultura de tecidos é utilizada para recuperar cultivares infectadas por vírus, pela micropropagação de plantas limpas obtidas após o cultivo de ápices caulinares. Esta técnica preserva, na maioria dos casos, a identidade do genótipo regenerado, uma vez que as células do meristema apical mantêm mais uniformemente a estabilidade genética (TORRES et al., 1998). No entanto, o cultivo in vitro pode conduzir à ampliação da variabilidade genética no material micropropagado, denominada, coletivamente, variação somaclonal (LARKIN \& SCOWCROFT, 1981).

A variabilidade genética introduzida pela cultura de tecidos é indesejada quando se objetiva a multiplicação de genótipos elite de batata, podendo ocasionar a perda de características agronômicas como cor de película, formato do tubérculo e até resistência a doenças (BINSFELD, 1992). No entanto, a variação somaclonal pode constituir ferramenta valiosa para um programa de melhoramento genético, principalmente de culturas de base genética estreita como a batata (HAWKES, 1978), ao produzir variantes com potencial para emprego no desenvolvimento de novas cultivares.

A caracterização e avaliação de acessos presentes em bancos de germoplasma são realizadas por meio de descritores de cada espécie (WETZEL et al., 2007). Em estudo que avaliou a dissimilaridade genética em progênies de batata, o formato de tubérculo foi o caráter com maior contribuição para a divergência em gerações de seedlings e de campo (SILVA et al., 2008). Devido à relevância das características de tubérculo para avaliação de dissimilaridade em clones de batata, estudos realizados visando a investigar a ocorrência de somaclones em batata em relação a esses descritores são igualmente importantes na seleção para fins de melhoramento. Além disso, a identificação de alterações em algumas características morfológicas em plantas de batata provenientes da cultura de calos vem sendo estudada, há bastante tempo, por alguns autores (AHLOOWALIA, 1981;AUSTIN \& CASSESLS, 1983; RAMULU et al., 1983), mas não há registros de estudos comparativos entre plantas regeneradas via organogênese direta e indireta e a ocorrência de variação somaclonal.

Nas cultivares de batata 'Asterix' e 'Macaca', importantes no contexto socioeconômico nacional e da região central do estado do Rio Grande do Sul, não há estudos relacionados à variação somaclonal. Isso constituiu um incentivo para a realização do presente estudo, que teve como objetivos identificar somaclones e avaliar o efeito do tempo de subcultivo e do tipo de explante sobre a ocorrência de variantes somaclonais nas duas cultivares, mediante a avaliação dos descritores mínimos de tubérculo.

\section{MATERIAL E MÉTODOS}

Os tubérculos de 'Asterix' e 'Macaca' utilizados para a obtenção de ápices caulinares foram cedidos pela Embrapa Clima Temperado, localizada em Pelotas, RS, estando previamente indexados para as principais viroses.

Os ensaios in vitro compreenderam quatro etapas, as quais foram conduzidas de maneira independente e separadas no tempo para as duas cultivares. Em todas as etapas, as culturas foram expostas à temperatura de $25^{\circ} \pm 3^{\circ} \mathrm{C}$, intensidade luminosa de $20 \mu \mathrm{mol} \mathrm{m} \mathrm{m}^{-2} \mathrm{~s}^{-1}$ e fotoperíodo de $16 \mathrm{~h}$ fornecido por lâmpadas fluorescentes brancas frias tipo luz do dia.

Na primeira etapa, os tubérculos foram plantados e, aproximadamente, 25 dias depois, foram isolados os ápices caulinares de cerca de $0,3 \mathrm{~cm}$, os quais foram inoculados em meio nutritivo MS (MURASHIGE \& SKOOG, 1962), na ausência de reguladores de crescimento. O período de cultivo dos ápices caulinares foi de 90 dias, sendo que, a cada 30 dias, os explantes foram transferidos para meio fresco de igual composição, sem subcultivo.

$\mathrm{Na}$ segunda etapa, foi efetuada a micropropagação, que se iniciou com a inoculação dos segmentos apicais caulinares em meio nutritivo MS acrescido dos fitorreguladores: 6-Benzilaminopurina (BAP), $1 \mathrm{mg} \mathrm{L}^{-1}$; Ácido a-Naftaleno Acético (ANA), 0,01 $\mathrm{mg} \mathrm{L}^{-1}$; e Ácido giberélico (GA3), $0,1 \mathrm{mg} \mathrm{L}^{-1}$. A partir do cultivo inicial, a cada 30 dias, as culturas foram micropropagadas, separando-se, em frascos diferentes, os segmentos apicais caulinares e os segmentos nodais originados por organogênese direta, bem como aqueles formados a partir de calos (organogênese indireta). Estes últimos, doravante, neste artigo, serão denominados derivados de calo. Foram efetuados 12 (clone novo) e 70 (clone velho) subcultivos, sendo as subculturas inoculadas em meio fresco de igual composição ao cultivo inicial. Os ensaios das duas cultivares foram conduzidos de maneira independente, em delineamento inteiramente casualizado, em esquema bifatorial $2 \times 3$, sendo testados os dois tempos de subcultivo (clone novo e velho) e os três tipos de explante (segmento apical caulinar, segmento nodal e 
derivado de calo), que originaram as plantas da primeira geração clonal, cujos tubérculos foram avaliados no presente estudo.

Nas duas últimas etapas, foi induzido o enraizamento das culturas em meio nutritivo de igual composição àquele empregado na cultura de ápices caulinares e efetuada a aclimatização. Esta foi realizada pela transferência das plantas obtidas para meio nutritivo MS de composição idêntica àquele usado no enraizamento, mas com o teor de sacarose reduzido para $1,5 \%$ e abertura gradativa da vedação do frasco, diariamente, durante 15 dias, até a retirada total da tampa.

Após aclimatizadas, as plantas foram transferidas, no outono de 2005, para vasos $n^{\circ} 15$ contendo substrato Plantmax ${ }^{\circledR}$ e cultivadas em casa de vegetação, onde produziram tubérculos regenerantes da geração inicial $\left(\mathrm{R}_{0}\right)$, os quais, após colhidos, foram armazenados em câmara refrigerada, a $20^{\circ} \mathrm{C}$, até a implantação dos ensaios em campo.

Os subcultivos, o enraizamento, a aclimatização das plantas e a produção de tubérculos regenerantes de primeira geração $\left(\mathrm{R}_{0}\right)$ foram efetuados preservando-se a identidade dos tratamentos. O plantio dos tubérculos $R_{0}$ foi realizado na primavera de 2005 . As plantas foram cultivadas no campo, em parcelas de 30 covas espaçadas a $0,30 \mathrm{mx} 0,80 \mathrm{~m}$, e manejadas de acordo com as recomendações para a cultura (PEREIRA et al., 2005). Os ensaios foram efetuados em área experimental localizada em Santa Maria, RS, Brasil (latitude: $29^{\circ} 43^{\circ} \mathrm{S}$, longitude: $53^{\circ} 48^{\circ} \mathrm{W}$ e altitude: $95 \mathrm{~m}$ ). O clima da região é temperado (MALUF, 2000) e o solo representativo do local é um Argissolo VermelhoAmarelo distrófico arênico, pertencente à unidade de mapeamento São Pedro (EMBRAPA, 1999).

As descrições de 'Asterix' e de 'Macaca' efetuadas por COLLARES (2002) e PEREIRA \& CASTRO (2006), respectivamente, foram usadas para a identificação dos somaclones. Foram utilizados os seis descritores mínimos de tubérculo, dentre o total de 33 considerados pelo Ministério de Agricultura, Pecuária e Abastecimento (MAPA) do Brasil para a realização dos ensaios de distinguibilidade, homogeneidade e estabilidade (DHE) necessários para a proteção de novas cultivares de batata (BRASIL, 1997). As avaliações foram feitas em 10 tubérculos regenerantes de segunda geração $\left(\mathrm{R}_{1}\right)$, por tratamento, logo após a colheita, conforme estabelecido por COLLARES (2002). Para cada característica, foi atribuída uma nota, de acordo com a escala estabelecida pelo MAPA, sendo avaliados: formato de tubérculo, profundidade dos olhos, aspereza da película, cor da película, cor da polpa e esverdeamento do tubérculo.
Após testar a normalidade dos dados pelo teste de Kolmogorov-Smirnov e a homogeneidade de variâncias pelo teste de Bartlett, as variáveis foram transformadas para a função $\sqrt{x+0,5}$, sempre que necessário, e submetidas à análise de variância. As médias foram comparadas pelo teste de Tukey $(\mathrm{P}<0,05)$. A precisão do experimento foi medida por meio da estatística acurácia seletiva (AS), calculada por $\sqrt{1-1 / \text { Fcal }}$. Utilizou-se o programa estatístico SISVAR (Sistema para Análise de Variância) para Windows ${ }^{\circledR}$, versão 4.0 (FERREIRA, 2000). As médias observadas para cada característica morfoagronômica foram, após, comparadas às notas atribuídas às cultivares em suas respectivas descrições e somente foram consideradas variantes somaclonais as médias que foram enquadradas em uma classe fenotípica diferente do padrão da cultivar respectiva.

\section{RESULTADOS E DISCUSSÃO}

Em 'Asterix' e 'Macaca' foram observados variantes somaclonais em quatro e dois dos seis descritores morfoagronômicos avaliados, respectivamente, contudo, apenas no formato e cor da polpa do tubérculo ocorreu variação somaclonal, simultaneamente, nas duas cultivares, os únicos descritores em que 'Macaca' apresentou somaclones. Em todos os descritores em que houve algum efeito significativo, observaram-se valores muito altos $(\geq 0,90)$ de acurácia seletiva, de acordo com a classificação proposta por RESENDE \& DUARTE (2007). Por conseguinte, houve alta precisão no acesso do verdadeiro valor genético dos tratamentos nas avaliações, uma vez que a correlação entre os valores fenotípicos observados e os preditos, para aquelas características em que houve variabilidade, foi muito alta.

As duas cultivares revelaram um comportamento diferenciado no que diz respeito às características cujos fenótipos foram alterados/ conservados após a cultura de tecidos, demonstrando que a ocorrência de variação somaclonal é influenciada pelo genótipo. Instabilidade fenotípica semelhante foi observada em clones derivados de meristemas das cultivares de batata 'Agrie dzeltenie' e 'Juku' submetidos a tratamento de termoterapia, sendo identificados somaclones para a intensidade de florescimento, a altura das hastes e a uniformidade das plantas (ROSENBERG et al., 2007). Em cultivares de bananeira (Musa domestica), regeneradas por um protocolo de multiplicação idêntico, há registros de estabilidade diferencial, obtidos, igualmente, pela avaliação de características morfológicas (RODRIGUES 
et al., 1998; SANTOS \& RODRIGUES, 2004). Em heliconia (Heliconia bihai cv. Lobster Claw I), foram observadas variantes relacionadas à variegação na folha, estatura da planta, coloração do pseudocale e pecíolo (RODRIGUES, 2008). Esses resultados ratificam outros estudos sobre a frequência de aparecimento de somaclones, que têm reconhecido ser a uniformidade clonal uma exceção e não uma regra (SKIRVIN et al., 1994).

Na sequência, será possível observar, também, diferenças entre as cultivares em relação ao efeito dos explantes e tempos de subcultivo - as duas fontes de variação estudadas - e suas interações. Em 'Asterix', para a cor da polpa do tubérculo não houve diferenças significativas entre os explantes nem entre os tempos de subcultivo, tampouco se observou interação entre os dois fatores, contudo, obteve-se uma média geral 2,97, que a classificaria como creme e que diverge da classe típica da cultivar - amarela clara. Já em 'Macaca', para a cor da polpa, em plantas regeneradas a partir de segmento apical caulinar e derivado de calo nos clones novo e velho, observaramse coloração amarela clara (nota 3), diferente do padrão da cultivar, que é branca (nota 1), indicando a ocorrência de variação somaclonal (Tabela 1). Com o emprego de segmentos nodais no clone novo, a cor foi classificada como creme e, no velho, os tubérculos conservaram a cor padrão da cultivar.

Em relação ao formato do tubérculo, em 'Asterix', não houve efeito significativo dos fatores principais nem da interação, com a média observada (3,43, equivalente a oval-alongado a longo) divergindo do fenótipo da cultivar oval (nota 2). Da mesma maneira, em 'Macaca', não houve diferença significativa entre os tubérculos, contudo, a média geral obtida $(1,48)$ permite classificá-los como redondos (nota 1), diferentes daqueles próprios de 'Macaca' - ovaiscurtos e achatados (nota 2).
Em 'Asterix', além da cor da polpa e formato do tubérculo, ocorreu variação somaclonal para a aspereza e a cor da película do tubérculo. Para a aspereza da película, houve efeito significativo apenas do tempo de subcultivo, com o clone novo apresentando média 2,13 e o velho, 3,67, ambas divergindo do padrão da cultivar (1, equivalente à película lisa), contudo, apenas no clone novo a variação observada promoveu uma classificação diferente para 'Asterix', que poderia integrar a classe áspera (nota 3). Para a cor da película, as plantas regeneradas de segmento apical caulinar (média 1,90) e derivado de calo $(1,80)$ não diferiram entre si, mas, sim, do segmento nodal $(1,30)$, porém nenhuma atingiu a nota padrão da cultivar, que é 2 , equivalente à película vermelha; o que permitiria classificá-las como película amarela.

Por outro lado, em 'Asterix' e 'Macaca' mantiveram-se estáveis, simultaneamente, a profundidade dos olhos e o esverdeamento do tubérculo. Apenas em 'Macaca', não se observaram variantes somaclonais para aspereza e cor da película do tubérculo.

Em 'Asterix', para a profundidade dos olhos e esverdeamento do tubérculo, não houve efeito significativo de nenhum dos fatores principais avaliados, tampouco da interação, observando-se médias de 1,13 e 1,10 , respectivamente. Para a profundidade dos olhos e esverdeamento, as notas foram diferentes do padrão (nota 1 para ambos, equivalente a olhos rasos e esverdeamento ausente/ muito fraco), mas isso não implicou enquadramento na classe seguinte: olhos médios e esverdeamento fraco (nota 3). Em 'Macaca', para essas duas características, observou-se um comportamento monomórfico, com todos os tubérculos avaliados recebendo nota 1 , que corresponde a olhos rasos e esverdeamento ausente ou muito fraco, típicos da cultivar.

Tabela 1 - Médias das notas atribuídas à cor da polpa e aspereza da película de tubérculos produzidos em plantas regeneradas a partir de segmento apical caulinar (SAC), derivado de calo (DC) e segmento nodal (SN) nos clones novo (N) e velho (V) da cultivar de batata 'Macaca'.

\begin{tabular}{lllcccc}
\hline \multicolumn{2}{c}{ Cor da polpa $^{\mathrm{I}}$} & & \multicolumn{3}{c}{ Aspereza da película $^{\text {II }}$} \\
\hline & $\mathrm{N}^{1}$ & $\mathrm{~V}^{2}$ & Média & $\mathrm{N}$ & $\mathrm{V}$ & Média \\
SAC & $3,00 \mathrm{aA} *$ & $3,00 \mathrm{bA}$ & 3,00 & $4,20 \mathrm{bA}$ & $4,20 \mathrm{aA}$ & 4,20 \\
$\mathrm{DC}$ & $3,00 \mathrm{aA}$ & $3,00 \mathrm{bA}$ & 3,00 & $2,40 \mathrm{aA}$ & $4,60 \mathrm{aA}$ & 3,50 \\
$\mathrm{SN}$ & $2,80 \mathrm{aB}$ & $1,60 \mathrm{aA}$ & 2,20 & $4,20 \mathrm{bA}$ & $4,60 \mathrm{aB}$ & 4,40 \\
Média & 2,93 & 2,53 & 2,73 & 3,60 & 4,47 & 4,03 \\
AS $^{* *}$ & 0,95 & & & 1,0 & & \\
\hline
\end{tabular}

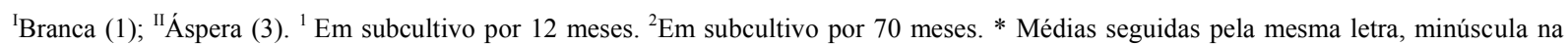
coluna e maiúscula na linha, não diferem significativamente pelo teste de Tukey em nível de $5 \%$ de probabilidade de erro. $* *$ AS $=$ acurácia seletiva (muito alta: $\geq 0,90$; alta: $\geq 0,70$ e $<0,90$; moderada: $<0,70$ e $\geq 0,50$; baixa: $<0,50$ ).

Ciência Rural, v.42, n.2, fev, 2012. 
Em 'Macaca', ainda, para a aspereza da película do tubérculo, houve interação entre os fatores principais (Tabela 1), verificando-se diferenças significativas entre algumas combinações de tipo de explante e tempo de subcultivo e, também, divergências em relação à nota atribuída à 'Macaca' $(3$, equivalente à áspera), mas que nunca atingiram a nota 5 , que corresponderia à reticulada. Já para a cor da película, não houve diferenças significativas entre os explantes nem relacionadas ao tempo de subcultivo, nem à interação entre os dois, e, também, não foi observada variação somaclonal, obtendo-se uma média 2 , que corresponde à película vermelha.

Os resultados observados no presente estudo indicam que a escolha de explantes para a micropropagação em função de seu grau de diferenciação não assegura estabilidade fenotípica na cultura de tecidos. Isso contraria a tese de que o aparecimento de variantes somaclonais é uma ocorrência mais comum em determinados tipos de explante (JAIN, 2001). Em heliconia (Heliconia bihai cv Lobster Claw I), a variação somaclonal ocorreu, também, em culturas regeneradas a partir de segmentos apicais caulinares (RODRIGUES, 2008), explantes considerados estáveis (JAIN, 2001).

Em relação ao tempo de subcultivo, constatou-se, no presente estudo, que, no período mínimo testado de 12 meses (12 subcultivos), já ocorreram variações somaclonais. Isso demonstra que foi excedido o tempo adequado para a manutenção de características morfoagronômicas importantes de 'Asterix' e 'Macaca'. Existe evidência direta da associação entre a variação somaclonal e o número de subcultivo na própria batata (BORDALLO et al., 2004), mas, também, em outras culturas, como na bananeira cv. Pacovan (SANTOS \& RODRIGUES, 2004) e no morangueiro - Fragaria $x$ ananassa (NEHRA et al., 1994). Em consequência, para minimizar a ocorrência de variantes, muitos laboratórios comerciais limitam o número de subcultivos, a partir de um explante, a um período de 12 meses, após o que todas as culturas estabelecidas a partir desse explante são descartadas (SKIRVIN et al., 1994). Para a cultivar Pacovan de bananeira, foi estabelecido o limite de seis subcultivos, após o que podem ocorrer variações indesejadas (SANTOS \& RODRIGUES, 2004). Em heliconia, a taxa de variação somaclonal observada $(61,40 \%)$ ocorreu após 18 subcultivos, o que indica que o limite máximo de subcultivos que proporciona estabilidade genética foi excedido na espécie ou na cultivar em uso (RODRIGUES, 2008).

\section{CONCLUSÃO}

Variantes somaclonais podem ser identificadas, nas cultivares de batata 'Asterix' e 'Macaca' pelo uso dos descritores mínimos de tubérculo. As cultivares de batata 'Asterix' e 'Macaca' são, igualmente, suscetíveis à ocorrência de variação somaclonal, porém esse fenômeno atua de maneira diferenciada em relação aos descritores mínimos de tubérculo nas duas cultivares. O tempo de subcultivo age diferencialmente sobre as características morfológicas. Doze meses de subcultivo já são suficientes para originar somaclones em ambas as cultivares de batata avaliadas. Segmentos apicais caulinares e segmentos nodais, originados por organogênese direta ou indireta, são explantes igualmente instáveis para a produção de tubérculossemente.

\section{REFERÊNCIAS}

AHLOOWALIA, B.S. Plant regeneration from callus culture in potato. Euphytica, v.31, n.3, p.755-759, 1981. Disponível em: $<$ http://www.springerlink.com/content/u561741n4p00p827/>. Acesso em: 29 set, 2011. doi: 10.1007/BF00039214.

AUSTIN, S.; CASSELS, A.C. Variation between plants regenerated from individual calli produced from separated potato stem callus cells. Plant Science Letters, v.31, n.1, p.107114, 1983. Disponível em: <http://www.sciencedirect.com/ science/article/pii/0304421183901347>. Acesso em: $30 \mathrm{abr}$, 2009. doi: 10.1016/0304-4211(83)90134-7.

BINSFELD, P.C. Obtenção e caracterização morfológica e isoenzimática de somaclones de batata (Solanum tuberosum L.). 1992. 100f. Dissertação (Mestrado em Agronomia) - Universidade Federal de Pelotas, Pelotas, RS.

BORDALLO, P.N. et al. Somaclonal variation on in vitro callus culture potato cultivars. Horticultura Brasileira, v.22, n.2, p.300-304, 2004. Disponível em: <http://www.scielo.br/ pdf/hb/v22n2/21035.pdf>. Acesso em: 29 abr, 2009.

BRASIL. Decreto - Lei no 2366, de Presidência da República. Decreto $\mathrm{n}^{\circ} 2366$ de 05 de novembro de 1997. Regulamenta a Lei n ${ }^{\circ}$ 9456, de 25 de abril de 1997, que institui a Proteção de Cultivares, dispõe sobre o Serviço Nacional de Proteção de Cultivares - SNPC, e dá outras providências. Diário Oficial (da República Federativa do Brasil), Brasília, n.216, p.2534225343, 7 de novembro de 1997, Seção 1.

COLLARES, E.A.V.S. et al. Caracterização morfológica de cultivares e clones avançados de batata por descritores necessários à proteção legal. Pelotas: Embrapa Clima Temperado, 2002. 50p. (Documentos, 98).

EMBRAPA. Sistema brasileiro de classificação de solos. Brasília: Embrapa Produções de informações, 1999. 412p.

FAO. AÑO INTERNACIONAL DE LA PAPA 2008. Nueva luz sobre un tesoro enterrado. Disponível em: <http:// www.potato2008.org/pdf/IYPbook-es.pdf>. Acesso em: 15 jun. 2010 
FERREIRA, D.F. Análises estatísticas por meio do Sisvar para Windows versão 4.0. In: REUNIÃO ANUAL DA REGIÃO BRASILEIRA DA SOCIEDADE INTERNACIONAL DE BIOMETRIA, 45, 2000, São Carlos, SP. Anais... São Carlos: UFSCar, 2000. p.255-258.

HAWKES, J.G. History of the potato. In: HARRIS, P.M. The potato crop: the scientific basis for improvement. London: Chapman \& Hall, 1978. p.1-14.

JAIN, S.M. Tissue cultured-derived variation in crop improvement. Euphytica, v.118, n.2, p.153-166, 2001. Disponível em: <http://www.springerlink.com/content/ w51544k4108q3750/>. Acesso em: 02 maio, 2009. doi: 10.1023/A:1004124519479.

LARKIN, P.J.; SCOWCROFT, W.R. Somaclonal variation: a novel source of variability from cell cultures for plant improvement. Theoretical and Applied Genetics, v.60, n.4, p.197-214, 1981. Disponível em: <http:// www.springerlink.com/content/t5140qq04260032k/>. Acesso em: 29 set, 2011. doi: 10.1007/BF02342540.

MALUF, J.R.T. Nova classificação climática do Estado do Rio Grande do Sul. Revista Brasileira de Agrometeorologia, v.8, n.1, p.141-150, 2000.

MURASHIGE, T.; NAKANO, R. Morphogenetic behavior of tobacco tissue cultures and implications of plant senescence. American Journal of Botany, v.52, n.8, p. 819-827, 1965.

MURASHIGE, T.; SKOOG, F. A revised medium for rapid growth and bioassays with tobbaco tissue culture. Plant Physiology, v.15, p.473-497, 1962. Disponível em: <http://onlinelibrary.wiley.com/ doi/10.1111/j.1399-3054.1962.tb08052.x/abstract>. Acesso em: 20 fev, 2011. doi:10.1111/j.1399-3054.1962.tb08052.x.

NASRIN, S. et al. Induction and evalution of somaclonal variation in potato (Solanum tuberosum L.). Online Journal of Biological Sciences, v.3, n.2, p.183-190, 2003. Disponível em: <http://docsdrive.com/pdfs/ansinet/jbs/2003/183-190.pdf>. Acesso em: 28 set, 2011.

NEHRA, N.S. et al. Effect of in vitro propagation methods on field performance of 2 strawberry cultivars. Euphytica, v.76, n.1, p.107-115, 1994.

PEREIRA, A.S. et al. Produção de Batata no Rio Grande do Sul. Pelotas: Embrapa/CPACT, 2005. 14p. (Circular técnica 48).

PEREIRA, A.S.; CASTRO, C.M. Batata 'Macaca' (Macaquinha, Rosa Redonda, Rosa Maçã). Pelotas: Embrapa Clima Temperado, 2006. 2p. (Documento, 147).
RESENDE, M.D.V. de; DUARTE, J.B. Precisão e controle de qualidade em experimentos de avaliação de cultivares. Pesquisa Agropecuária Tropical, v.37, n.3, p.182-194, 2007. Disponível em: <http://www.revistas.ufg.br/index.php/pat/ article/view/1867>. Acesso em: 28 set, 2011.

SANTOS, C.C.C.; RODRIGUES, P.H.V. Variação somaclonal em mudas micropropagadas de bananeira, cultivar Pacovan. Bragantia, v.63, n.2, p.201-205, 2004. Disponível em: <http:/ /www.scielo.br/scielo.php?script $=$ sci_arttext\&pid $=$ S0006$87052004000200005 \&$ lang=pt $>$. Acesso em: 10 maio, 2011.

SILVA, G.O; et al. Importância de caracteres na dissimilaridade de progênies de batata em gerações iniciais de seleção. Bragantia, v.67, n.1, p.141-144, 2008. Disponível em: <http:/ /www.scielo.br/pdf/brag/v67n1/a17v67n1.pdf>. Acesso em: 01 nov. 2011.

SKIRVIN, R.M. et al. Sources and frequency of somaclonal variation. Hortscience, v.29, n.11, p.1232-1237, 1994.

RAMULU, K.S. et al. Phenotypic variation and ploidy level of plants regenerated from protoplasts of tetraploid potato (Solanum tuberosum L. cv. 'Bintje'). Theoretical and Applied Genetics, v.65, n.4, p.329-338, 1983. Disponível em: <http:/ /www.springerlink.com/content/g134363703333357/>. Acesso em: 08 maio, 2011. doi: 10.1007/BF00276573.

RODRIGUES, P.H.V. et al. Influência do número de subcultivos na ocorrência de variação somaclonal em mudas de bananeira cv. Nanicão, no Vale do Ribeira - SP. Revista Brasileira de Fruticultura, v.20, p.74-79, 1998.

RODRIGUES, P.H.V. Somaclonal variation in micropropagated Heliconia bihai cv Lobster Claw I plantlets (Heliconiaceae). Sicentia Agricola, v.65, n.6, p.681-684, 2008. Disponível em: $<$ http://www.scielo.br/scielo.php?script=sci_arttext\&pid=S0103$90162008000600017 \& \operatorname{lng}=$ en\&nrm=iso\&tlng=en $>$. Acesso em: 29 set. 2011.

ROSENBERG, V. et al. Variation of agronomic traits of potato somaclones produced by meristem culture. 2007. Disponível em: < http://www.eria.ee/public/files/LA_artikkel.pdf $>$. Acesso em: 29 abr, 2009.

TORRES, L.S. et al. Cultura de ápices caulinares e recuperação de plantas livres de virus. In: TORRES, A. et al. (Ed.). Cultura de tecidos e transformação genética de plantas. Brasília, DF: EMBRAPA-SPI/ EMBRAPA-CNPH, 1998. V.1, p.87-132.

WETZEL, M.M.V. da S.; FERREIRA, F.R. Sistema de curadorias de germoplasma. In: NASS, L.L. (Ed.). Recursos genéticos vegetais. Brasília, DF: Embrapa Recursos Genéticos e Biotecnologia, 2007. p.121-144. 